\title{
Optical Techniques for Shock Visualization and Detection
}

G. Adamovsky

Lewis Research Center

Cleveland, Ohio

and

D.K. Johnson

The University of Akron

Akron, Ohio

Prepared for the

Conference on Optical Techniques in Fluid, Thermal, and Combustion Flow sponsored by the Society for Photo-Optical Instrumentation Engineers San Diego, California, July 9-14, 1995

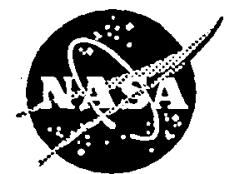

National Aeronautics and Space Administration

Enon: con

(1i)! 21905

UASEY RESERRCHCEMTER

IBRTiritis:

lampoi!, !hali!l 
. 
pattern strong high power light sources have to be used. Another drawback is due to the fact that the sharpness (or contrast) of the pattern generated by the instrument depends on the distance from the inhomogeneity in the flow to the observation screen. To obtain a good quality visualized image of the flow on the screen, it has to be placed reasonably far away from the flow. These drawbacks seriously limit the applicability of the shadowgraph, especially to airborne systems.

An approach we propose in this paper may help to minimize the problems mentioned above. It uses a narrow pencil beam instead of a wide collimated one. The pencil beam is scanned through the flow and inhomogeneities in the flow alter the direction of the beam propagation. It has been reported already that shocks may cause laser beam scattering in a free jet ${ }^{6}$ and in supersonic flow with a blunt body,8. The present paper describes and evaluates the interaction of a pencil beam with shocks generated within converging-diverging nozzles.

\section{OPTICAL SCANNING TECHNIQUES}

The scanning mode shadowgraphs have a higher optical power density throughput than conventional shadowgraphs. A common feature in these instruments is a scanning element that makes a narrow beam of light scan through the aperture of the system in a time sequential manner. Among various beam scanning mechanisms some of the best known are electro-mechanical and acousto-optical. Electro-mechanical scanners are optical mirrors or prisms that reflect light in a certain direction according to the law of reflection. By changing the position of the reflecting surface with respect to the incident beam the direction of the reflected beam also will be changed. Two basic types of electromechanical scanners, linear and angular, are represented.

In a system with a linear scanner (Fig. 1) a reflecting mirror or prism moves parallel to the flow direction and reflects the incident beam at a right angle. Thus, we scan the beam through a region in the nozzle where we expect the shock to be.

In a sensing system with an angular scanner (Fig. 2) a reflecting mirror or prism rotates around an axis producing a sector of light. The axis is located at the reflecting surface of the scanner from which the incident beam reflects. The scanner is a part of a transmitter and is located in the vicinity of the test section. The light beam reflected from the scanner passes through a collimating lens. The scanner and the collimating lens are positioned in a such way that the focal point of the lens lies on the axis of the scanner.

The principle of acousto-optical scanners is similar to electro-mechanical ones. The major difference is that the electro-mechanically driven reflecting surface is replaced by an acousto-optical deflector. The deflector is placed at the focal point of the collimating lens in such a way that the beam that exits the lens is always normal to the flow direction. 


\section{DESCRIPTION OF EXPERIMENT}

The experiment has been conducted using two converging-diverging (CD) nozzles with transparent windows in the test sections. A description of the CD nozzle principle can be found in a number of publications 9,10 . The CD nozzles were connected to a $25.4 \mathrm{~mm}$ diameter shop air supply line. Both nozzles had minimum throats with a square shape but their profiles and area variations were different. The area profile of the first nozzle was computed for a maximum Mach number of 1.8 and the dimensions of the minimum throat were $13.9 \times 13.9 \mathrm{~mm}^{2}$. The other nozzle had the throat dimensions 17.9 $x 17.9 \mathrm{~mm}^{2}$ and the area was computed for Mach number 2.3. Both nozzles had windows in their outer walls in the region of the minimum throat. By shining the beam through the windows, perpendicular to the direction of the flow, one could observe the effect of the flow on the spatial distribution of the beam intensity after passing through the test cell.

The configuration of the experiment is displayed in Fig. 3 . The experimental setup consists of two laser systems LS1 and LS2, a CD nozzle with transparent windows, a beam splitter B, beam splitting prism P, two photo detectors (CCD array and photo camera), and signal processing equipment. The laser system LS1 contains a $3 \mathrm{~mW} \mathrm{HeNe}$ laser $\mathrm{L} 1$ and collimating device $\mathrm{Cl}$. This system creates a wide collimated beam with uniformly distributed intensity and is a conventional shadowgraph. The laser system LS2 consists of a single $0.5 \mathrm{~mW}$ HeNe laser which emits a narrow pencil beam . Both beams, the pencil beam and the collimated one, are sent through the beam splitting prism $P$ in such manner that they exit the beam splitter superimposed and aligned in the same direction of propagation. The combined beam then passes through the windows of the CD nozzle. Finally, via the beam splitter B, the beam reaches the photo camera and the CCD array . The intensity distribution obtained by the CCD array is observed on an oscilloscope. Both, the photo camera and oscilloscope, are connected to a computer for data acquisition and analysis.

With the configuration described above, we can analyze the flow at the same location using two different techniques. The shock is visualized by a collimated beam produced by the laser system LS1 and the resultant shadow is observed. The pencil beam from laser system LS2 also penetrates the flow in the vicinity of the shock. With this configuration the laser systems LS1 and LS2 can be used independently from each other under the same flow conditions. To evaluate phenomena of laser beam interactions with shocks, the pencil beam is scanned across the test section transverse to the flow direction. This is done by placing the beam splitting prism $\mathrm{P}$ on a translation stage (not shown in the Fig. 3) which is controlled electronically. When the pencil beam passes through regions in the flow with strong changes in density the circular cross sectional shape of the beam becomes deformed.

Despite of similarities in the CD nozzles used in the experiment their operational regimes are quite different. The nozzle with the smaller minimum throat area was operated with higher up-stream and down-stream pressures than the nozzle with the 
larger throat area. The lower pressures in the latter resulted in a lower air density and also a lower refractive index.

\section{RESULTS AND DISCUSSION}

The results of the experiment using the $C D$ nozzle with the smaller minimum throat obtained by the photo camera and CCD array are shown in Figs. 4, 5, and 6 . Figure 4 contains cross sectional intensity distributions of the pencil beam, after it passes through the test section of the nozzle, under three conditions, no flow (Fig. 4a), with the flow but no shocks (Fig. 4b), and with the beam intersecting the shock (Fig. 4c). It can be seen from these pictures that the interaction of a pencil beam with a shock produces a smearing of the beam. The smearing and tail associated with it occur in the direction of flow. The phenomenon is explained by the fact that the air density of a subsonic flow downstream of the shock is higher than the air density of a supersonic flow upstream of it. The air density gradient causes the beam to refract in the direction of flow. Thus, the beam smearing and tail result.

Using the smaller nozzle with CCD array placed $1 \mathrm{~m}$ away from the test cell, Fig. 5 contains the intensity distribution of the pencil beam at three different locations in the nozzle under flow conditions which yield a shock. From Fig. 6 (the shadowgraph of the test cell under the same conditions) we can readily identify the existence of a shock from the bump on the graph. The intensity profile of the pencil beam is represented in "Fig. 5 as a pulse-like signal of almost constant amplitude due to saturation of the CCD array. A significant increase in the width of the pulse is observed when the beam is passing through the shock. This increase is also a manifestation of the beam smearing and tail.

Similar results have been obtained using the $C D$ nozzle with the larger minimum throat. However, an attempt to use the shadowgraph to observe the shock has ended in a low contrast pattern with the shock being hardly seen by the CCD. Figure 8 shows a signal obtained using the shadowgraph and the CCD array placed at a distance of 1 meter from the nozzle. At the same time the pencil beam produced a quite noticeable tail (See Fig 7). Locating the CCD array at $4 \mathrm{~m}$ distance has produced slight improvement in the contrast of the pattern obtained using shadowgraph. The intensity distribution of the laser pencil beam after passing through the shock is accompanied, again, by a significant tail. Figures 9 and 10 show data from the scanning pencil beam approach and shadowgraph respectively with the CCD placed at a distance of 4 meters from the test cell.

The data obtained using both $C D$ nozzles have shown such similar features as refraction of the pencil beam caused by the shock. At the same time the laser light scattering by the shocks is insignificant and is barely seen. The refractive effects have been manifested as a substantial increase in the beam width and may be used as an indicator of the presence of the shock. The experiment has shown that these refractive effects are stronger than those that govern the shadow formation. It makes it possible to construct a compact shock "visualizing" system. Such a portable flow visualizing system could find applications at test facilities. One of the shortcomings of the technique is the 
need to provide electric power to the scanning element. Providing this problem is solved, the technique could also become a good candidate for such airborne instrumentation as a normal shock position sensor.

\section{ACKNOWLEDGMENT}

D. K. Johnson acknowledges the support of the NASA Lewis Research Center (NASA Cooperative Agreement NCC 3-283).

\section{REFERENCES}

1. A. H. Shapiro, The Dynamics and Thermodynamics of Compressible Fluid Flow, Vol. I, The Ronald Press Company, New York, 1953.

2. W. Merzkirch, Flow Visualization, Academic Press, Orlando, 1987.

3. Physical Measurements in Gas Dynamics and Combustion, R. W. Ladenburg, B. Lewis, R. N. Pease, and H. S. Taylor, eds., Vol. IX, High Speed Aerodynamic and Jet Propulsion, Princeton University Press, Princeton, New Jersey, 1954.

4. F. Amiranoff, R Fedosejevs, R. F. Schmalz, R Sigel, and Yung-lu Teng, "Laserdriven shock-wave studies using optical shadowgraphy," Physical Review A, Vol. 32, No. 6, pp. 3535-3546, 1985.

5. R. W. Lewis, R. E. Teets, J. A. Sell, and T. A Seder, "Temperature measurements in a laser-heated gas by quantitative shadowgraphy," Appl. Opt., Vol. 26, No. 17, pp. 3695-3704, 1987.

6. J. Panda, "Wide angle light scattering in shock-laser interaction", AIAA Journal, Vol. 34, No. 3, March 1996 (to be published).

7. J. Panda and G. Adamovsky, "An experimental investigation of laser light scattering by shock waves," 33rd Aerospace Sciences Meeting and Exhibit, Reno, Nevada, January 9-12, 1995 ( Paper AIAA 95-0518).

8. J. Panda and G. Adamovsky, "Laser light scattering by shock waves," Physics of Fluids, Sept., 1995 (to be published).

9. G. Adamovsky and J. G. Eustace, "Optical techniques for determination of normal shock position in supersonic flows for aerospace applications," in Optical Testing and Metrology III: Recent Advances in Industrial Optical Inspection, C. P. Grover, ed., Proc. SPIE Vol. 1332, pp. 750-756, 1990.

10. S. I. Hariharan, D. K. Johnson, and G. Adamovsky, " A theory and experiment for detecting shock locations," in Laser Application in Combustion and Combustion Diagnostics II, R. J. Locke, ed., Proc. SPIE Vol. 2122, pp. 195-205, 1994. 


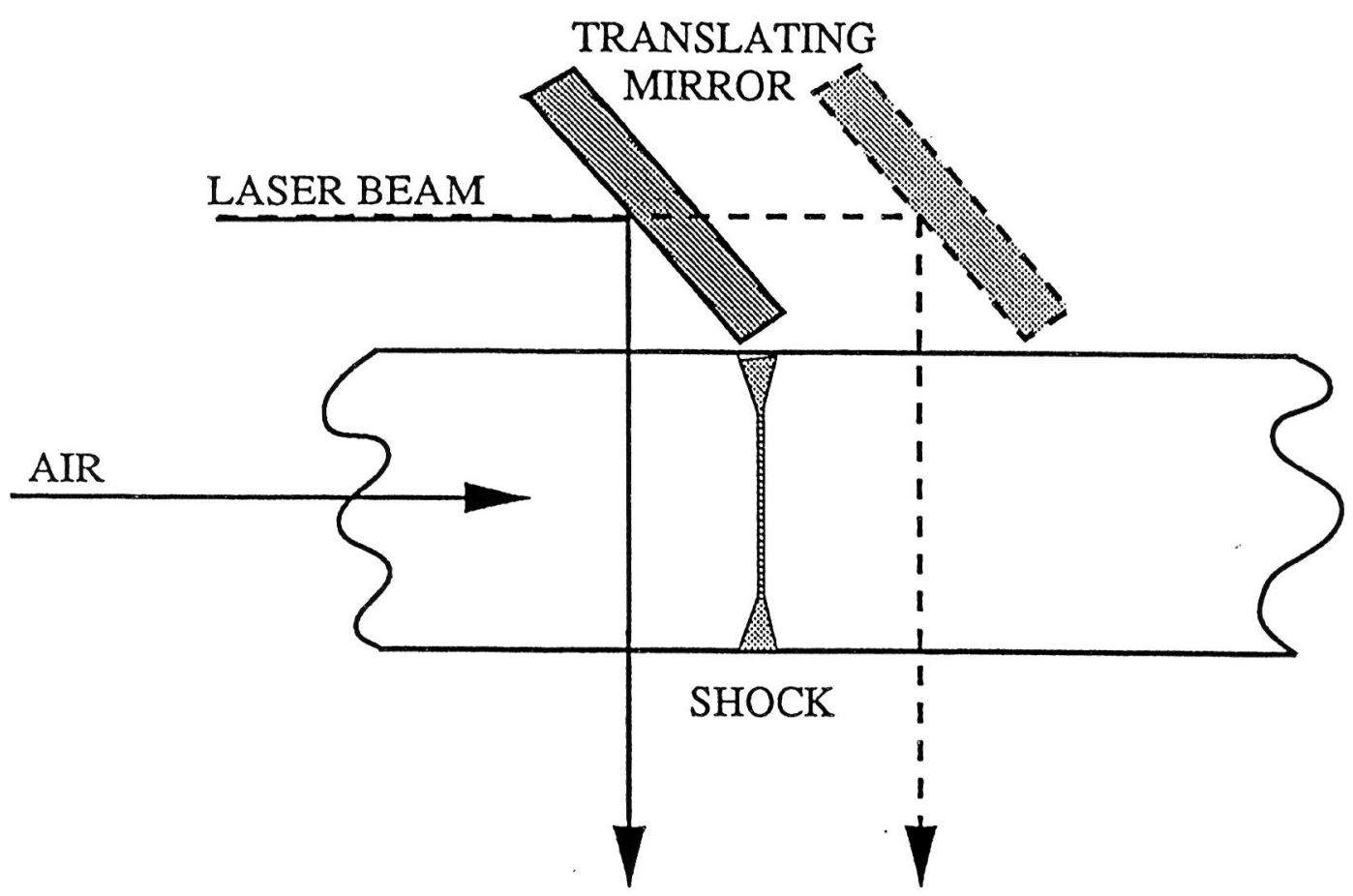

FIG. 1. System with linear scanner

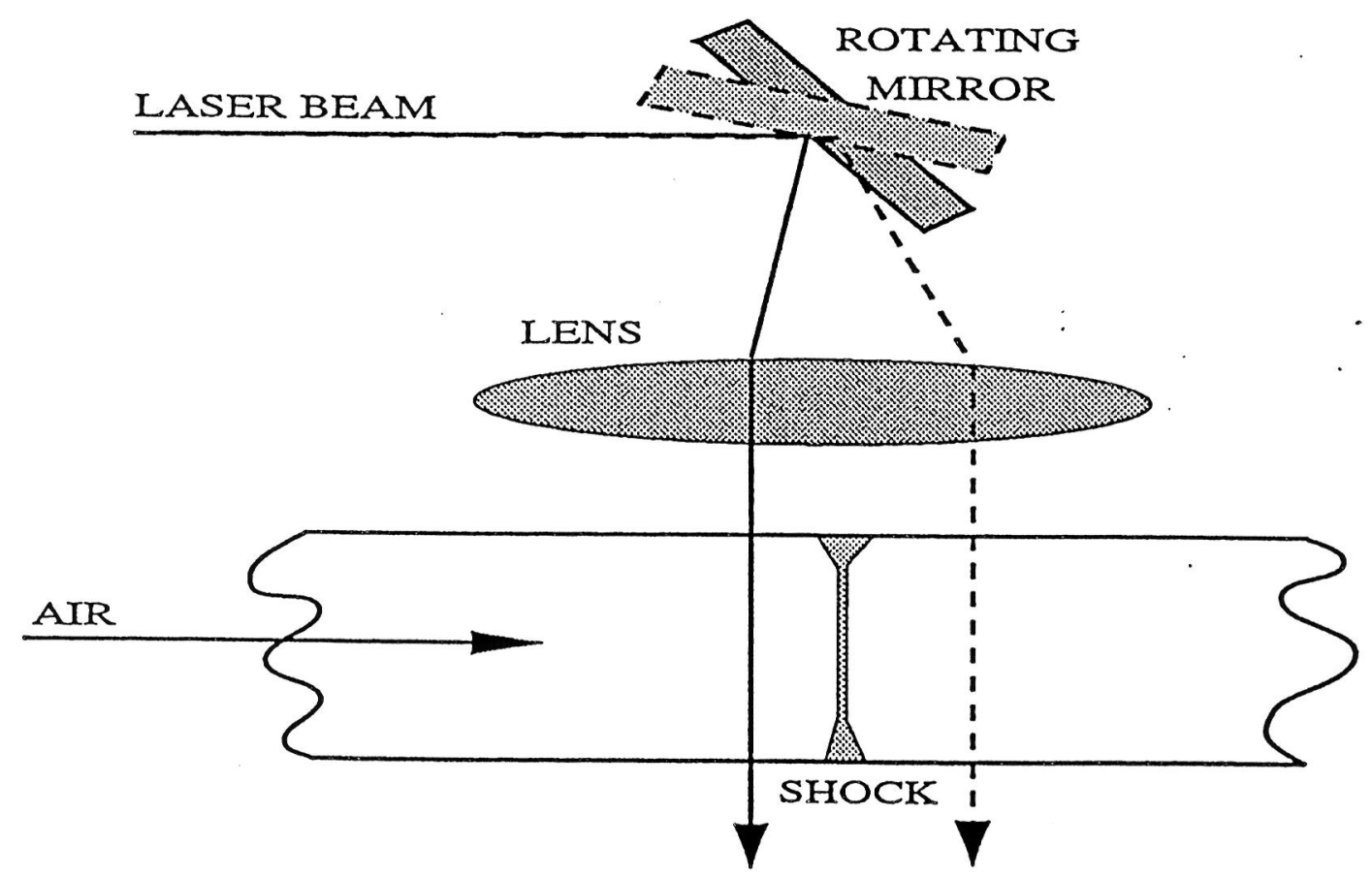

FIG. 2. System with angular scanner 


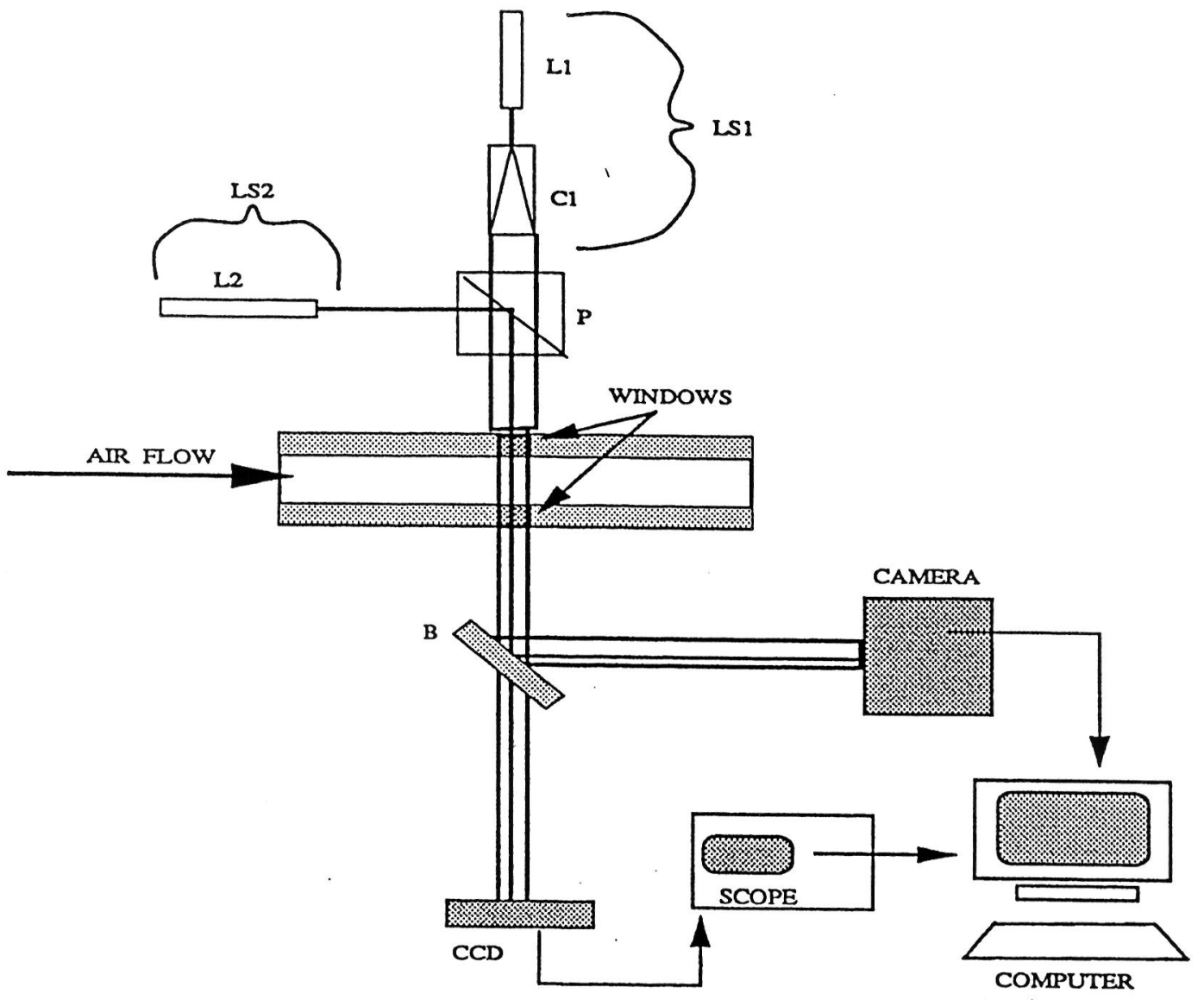

FIG. 3. Principle configuration of the experiment

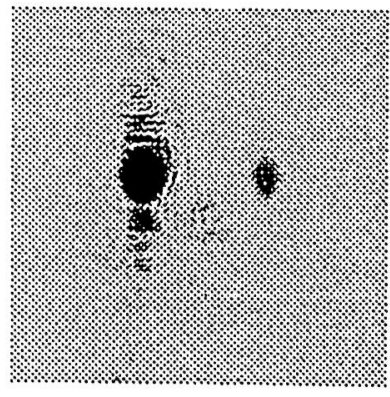

(a)

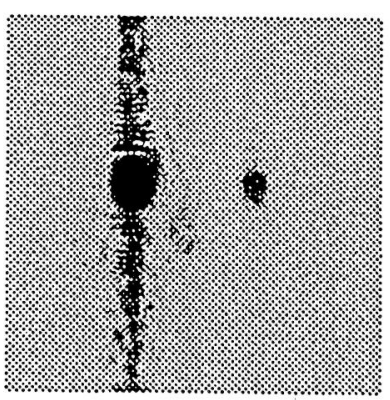

(b)

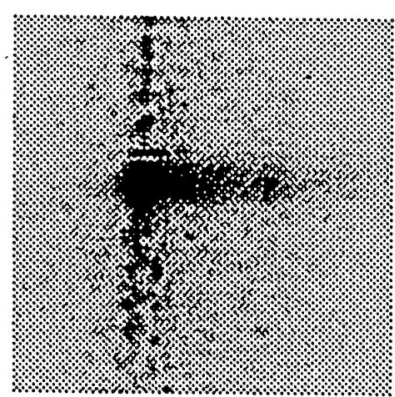

(c)

FIG. 4. Photographs of a laser beam after passing through the windows of the nozzle.

(a) - no flow

(b) - flow without shock

(c) - beam intersects a shock 


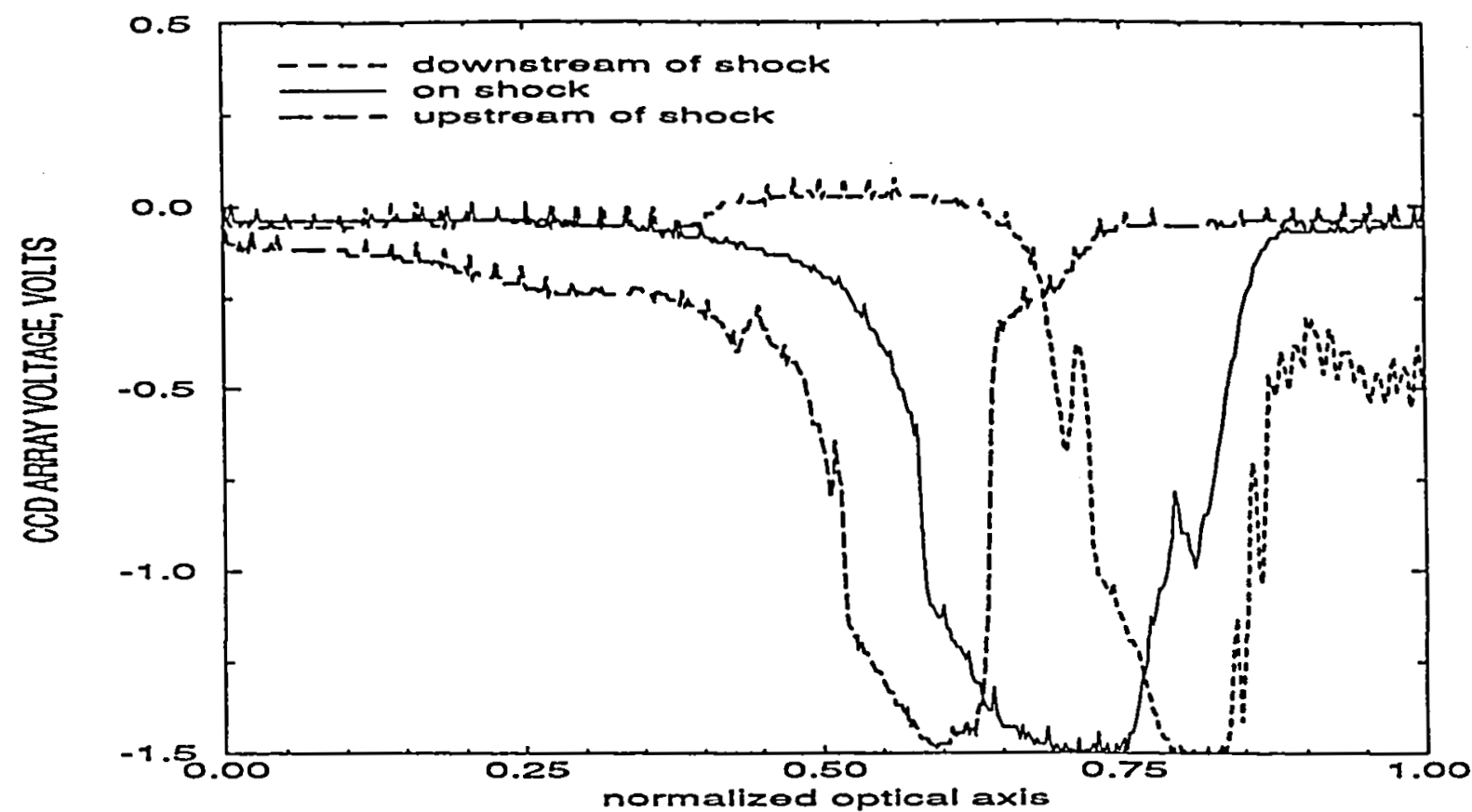

FIG. 5. Intensity distribution of the pencil beam in smaller nozzle at three locations under flow conditions which yield a shock.

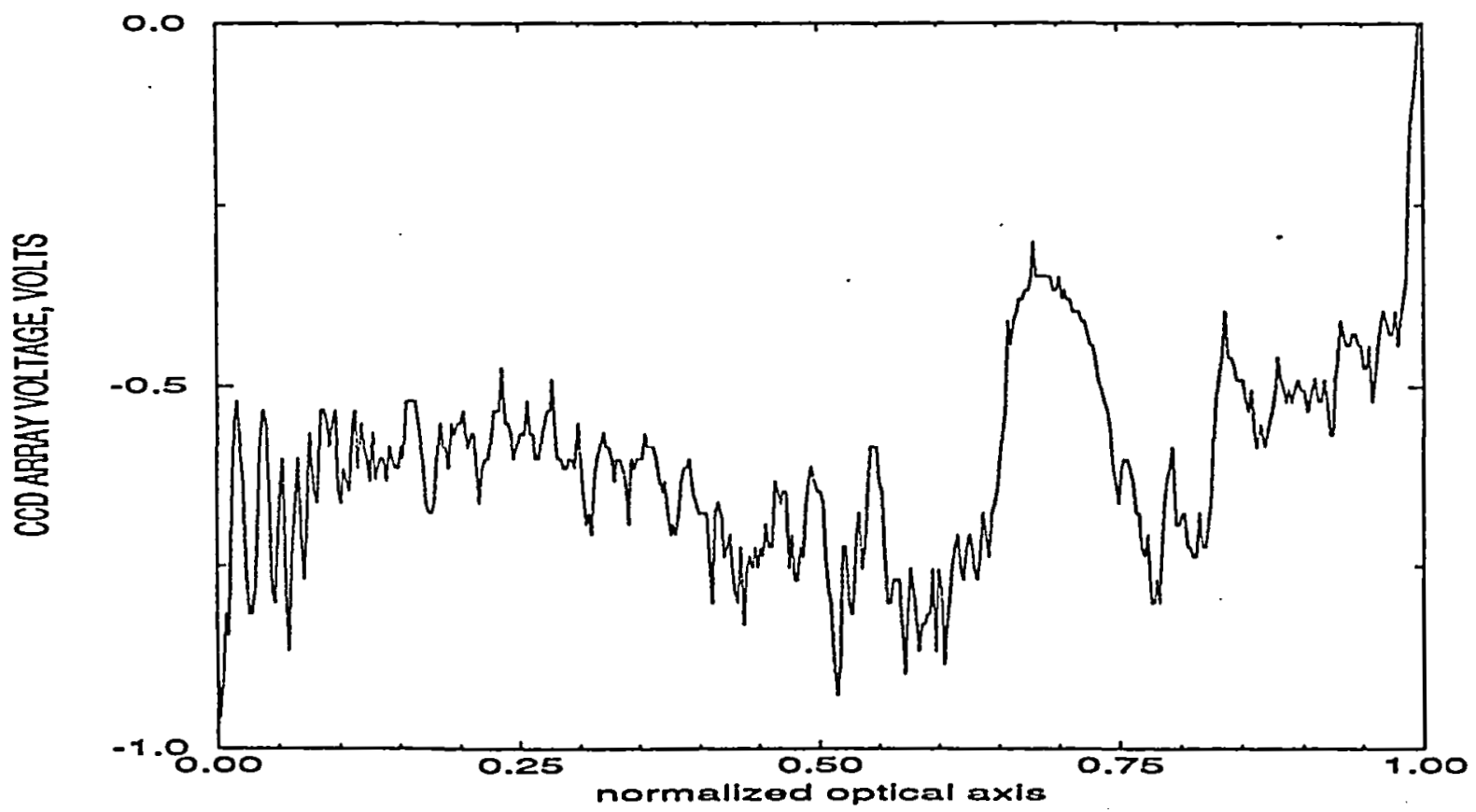

FIG. 6. Shadowgraph image of the test cell under same conditions as in Fig. 5. 


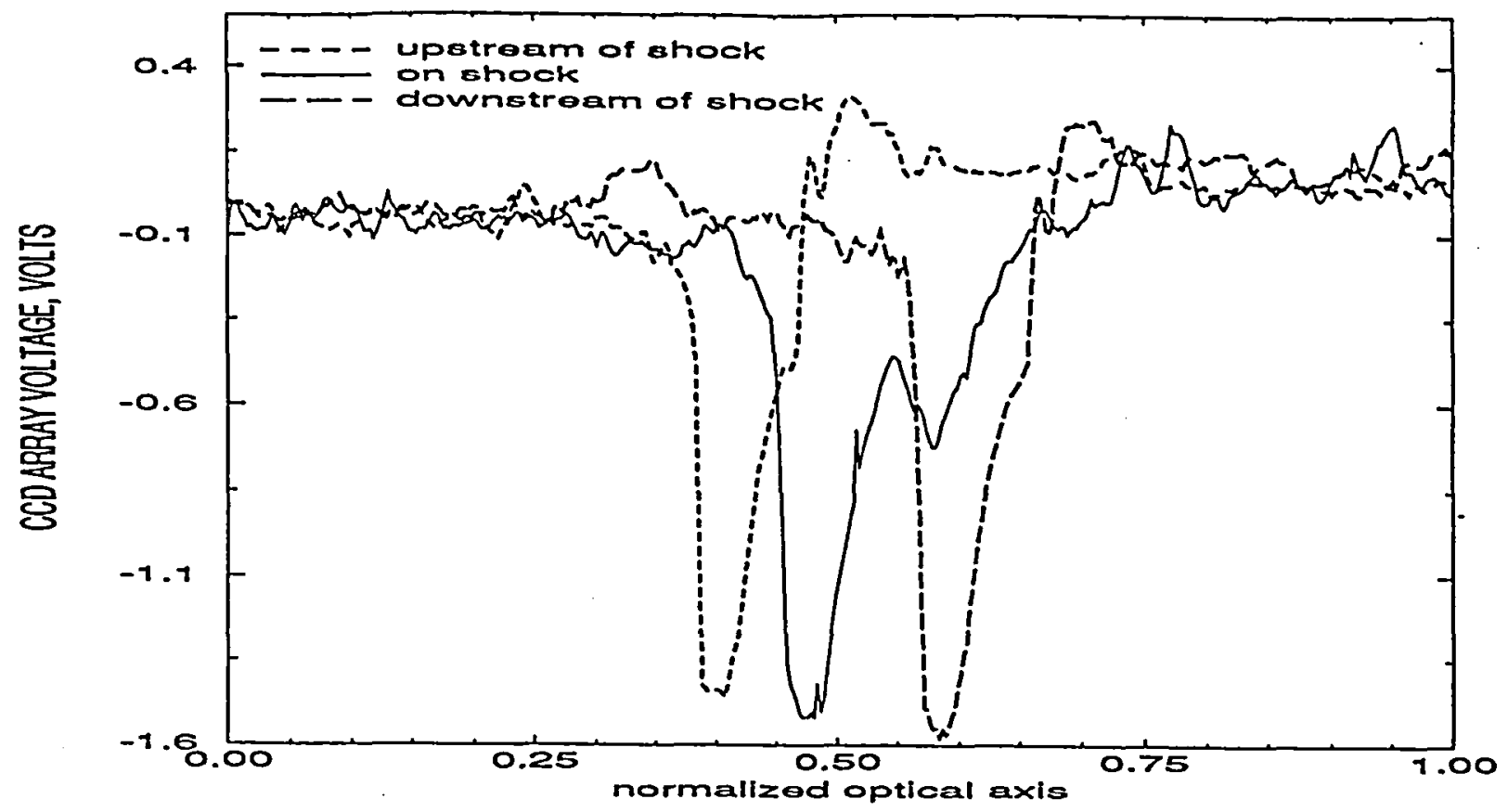

FIG. 7. Intensity distribution of the pencil beam in larger nozzle at three locations under flow conditions which yield a shock.(Distance from screen to test cell is $1 \mathrm{~m}$.)

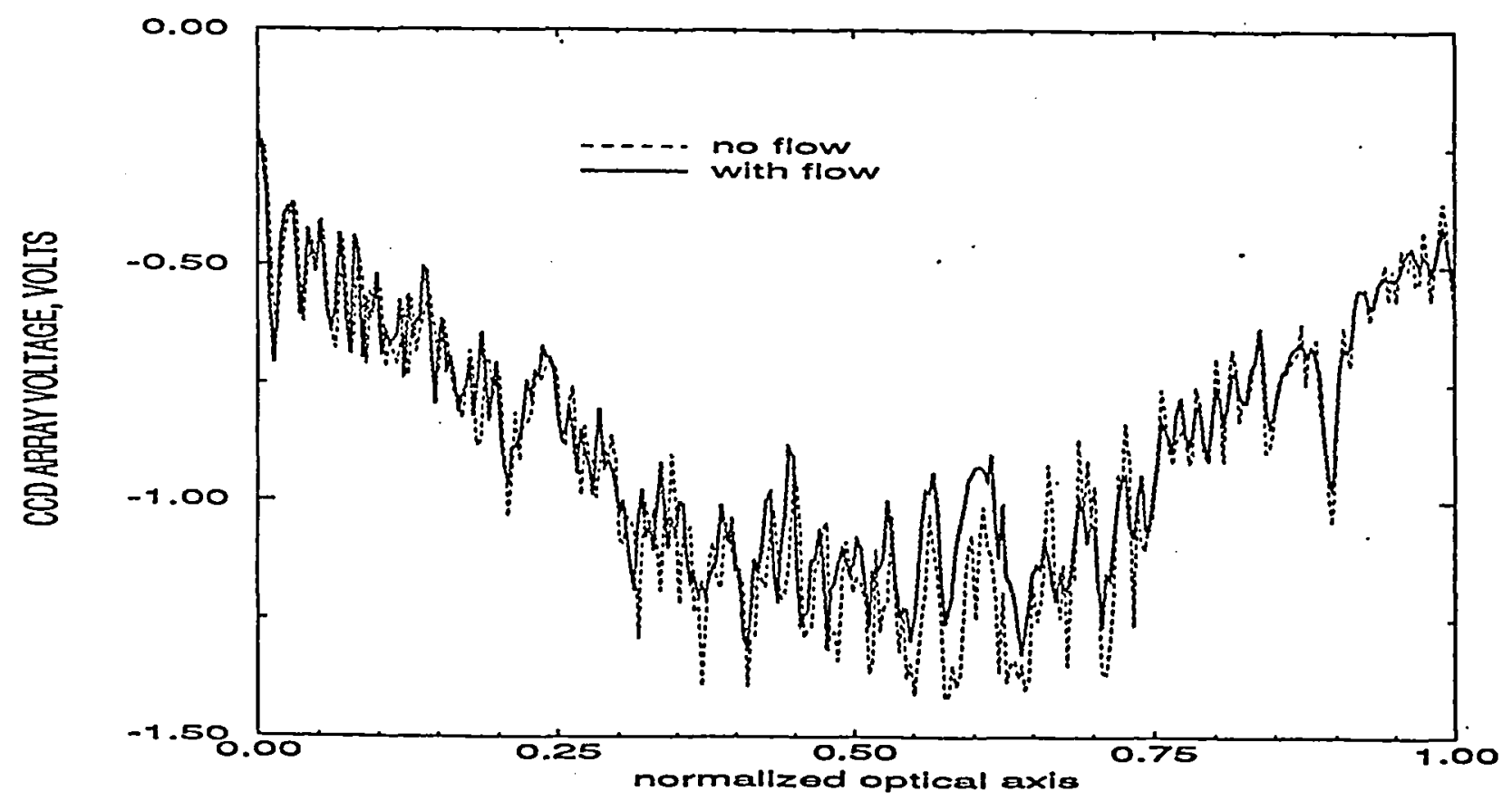

FIG. 8. Shadowgraph image of the test cell under same conditions as in Fig. 7. 


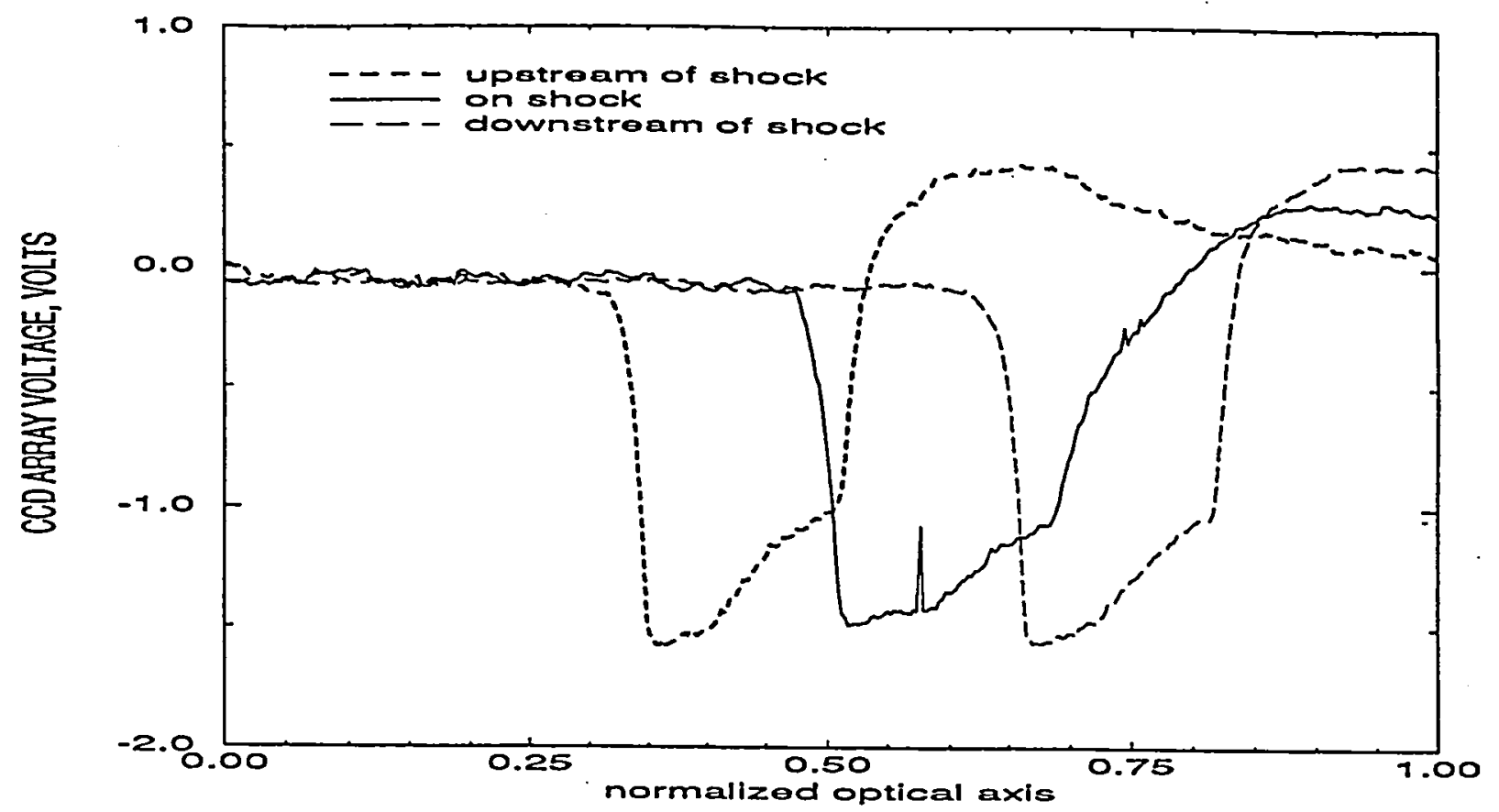

FIG. 9. The same as in Fig. 7. but taken at $4 \mathrm{~m}$ distance

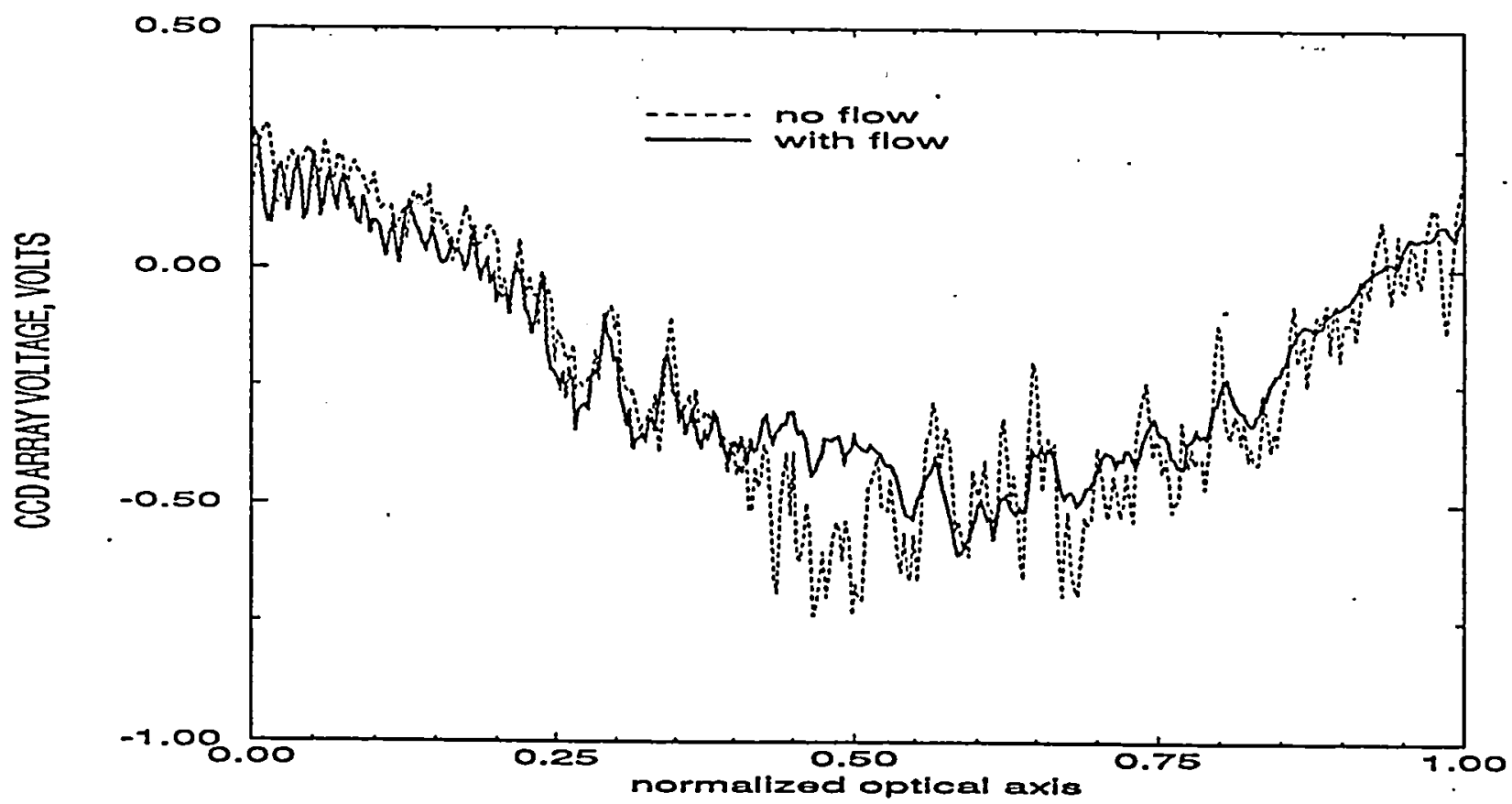

FIG. 10. Same as Fig. 8. but taken at the $4 \mathrm{~m}$ distance. 

Public reporting burden for this collection of information is estimated to average 1 hour per response, including the time for reviewing instructions, searching existing cata sources, gathering and maintaining the data needed, and completing and reviewing the collection of inlormation. Send comments regarding this burden estimate or any other aspect of this Davis Highway. Suite 1204. Arlington. VA 22202-4302, and to the Office of Management and Budget, Paperwork Reduction Project (0704-0188). Washington, DC 20503.

\begin{tabular}{|l|c|c|}
\hline 7. AGENCY USE ONLY (Leave blank) & $\begin{array}{c}\text { 2. REPORT DATE } \\
\text { October } 1995\end{array}$ & $\begin{array}{r}\text { 3. REPORT TYPE AND DATES COVERED } \\
\text { Technical Memorandum }\end{array}$ \\
\hline
\end{tabular}

4. TITLE AND SUBTITLE

Optical Techniques for Shock Visualization and Detection

6. AUTHOR(S)

G. Adamovsky and D.K. Johnson

7. PEAFORMING ORGANIZATION NAME(S) AND ADDRESS(ES)

National Aeronautics and Space Administration

Lewis Research Center

Cleveland, Ohio 44135-3191

9. SPONSORING/MONITORING AGENCY NAME(S) AND ADDRESS(ES)

National Aeronautics and Space Administration

Washington, D.C. 20546-0001
5. FUNDING NUMBERS

WU-505-62-50

8. PERFORMING ORGANIZATION REPORT NUMBER

E-9788-1

10. SPONSORING/MONITORING AGENCY REPORT NUMBER

NASA TM-107081

11. SUPPLEMENTARY NOTES

Prepared for the Conference on Optical Techniques in Fluid, Thermal, and Combustion Flow sponsored by the Society for PhotoOptical Instrumentation Engineers, San Diego, California, July 9-14, 1995. G. Adamovsky, NASA Lewis Research Center and D.K. Johnson, The University of Akron, Akron, Ohio 44325. Responsible person, G. Adamovsky, organization code 2540, (216) 433-3736.

12a. DISTRIBUTION/AVAILABILTY STATEMENT 12b. DISTRIBUTION CODE

Unclassified - Unlimited

Subject Categories 74 and 35

This publication is available from the NASA Center for Aerospace Information, (301) 621-0390.

13. ABSTRACT (Maximum 200 words)

While the classical methods of shadowgraph and schlieren do yield a shadow in the neighborhood of a shock, they often suffer from low power densities and the need for relatively long distances. Scanning methods may help in solving these problems. The paper describes various scanning techniques, presents experimental data obtained by mechanical scanning, and identifies conditions at which the data were taken.

14. SUBJECT TERMS

Supersonic flow; Normal shocks; Flow visualization; Refractions; Optical sensing

17. SECURTY CLASSIFICATION OF REPORT Unclassified
18. SECURITY CLASSIFICATION OF THIS PAGE Unclassified
19. SECURITY CLASSIFICATION OF ABSTRACT Unclassified 
National Aeronautlcs and

Space Administration

Lewis Research Center

21000 Brookpark Rd.

Cleveland, $\mathrm{OH}$ 44135-3191

OHiclal Business

Penally for Privale Uso \$300

POSTMASTER: If Undeliverable - Do Nol Return 